\title{
A study on urban economic vulnerability evaluation system
}

\author{
YUAN Haihong ${ }^{1,2,3},{ }^{*}$ NIU Fangqu ${ }^{1}$, GAO Xiaolu ${ }^{1}$
}

1. Key Laboratory of Regional Sustainable Development Modeling, Institute of Geographic Sciences and Natural Resources Research, CAS, Beijing 100101, China;

2. University of Chinese Academy of Sciences, Beijing 100049, China;

3. School of Architectural Civil Engineering and Environment, Ningbo University, Ningbo 315211, Zhejiang, China

\begin{abstract}
Chinese cities face high and rapidly increasing exposure to disasters. Reducing disaster vulnerability is a direct and effective countermeasure for disaster management and risk reduction, which requires first and foremost objective assessment of the vulnerabilities of societies and economies. Assessment of economic vulnerability is a significant step in risk evaluation, a prerequisite for effective disaster prevention planning and an important base for emergency management. This paper develops a model for assessing economic vulnerability, which takes into account of the size of enterprises, the vulnerability and importance of various industrial sectors and economic density. Based on the model, this paper develops an urban economic vulnerability evaluation system and applies it to Haidian District in Beijing, the results help identify where in its 647 blocks are highly and very highly vulnerable in terms of economies, and it provides useful and practical information for pre-disaster prevention planning, disaster preparedness and emergency management. The economic vulnerability assessment model and the system developed in this study make it possible for the government to quickly evaluate the general economic vulnerability and identify the specific vulnerable areas, making contribution to disaster management information system and decision support system.
\end{abstract}

Keywords: economic vulnerability; assessment model; evaluation system; risk management; Haidian District in Beijing

\section{Introduction}

In the context of frequent disasters and growing losses around the world, a lot of global attention is being paid to study disaster risk (Yin, 2009). Due to its strategic role in regional and national socioeconomic development, the issue of disaster risk reduction in large and

Received: 2015-01-23 Accepted: 2015-03-30

Foundation: National Natural Science Foundation of China, No.41101119; No.41171138; Key Project of Chinese Academy of Sciences, No.KZZD-EW-06

Author: Yuan Haihong (1986-), PhD Candidate, specialized in disaster risk assessment.

E-mail: haihongyuan321@126.com

"Corresponding author: Niu Fangqu (1979-), PhD and Assistant Professor, E-mail: niufq@igsnrr.ac.cn 
super-large cities is particularly important. Socioeconomic transformation and urbanization is going on in China at a quick pace, serious resource and environment problems, coupled with population and industry agglomeration, urban expansion, industry upgrading and structural adjustment of urban space, result in more complex and vulnerable socioeconomic system, reduced security coefficient, and many potential contributors to disasters, like the high population density (Niu, 2004), grave hazards (from industries) (Yu and $\mathrm{Yu}, 2004$ ) and imperfect infrastructures (Jiang and Jiang, 2012). Security accidents occur frequently against this background (CAM, 2005), posing severe challenges to urban public security management. On the other hand, urban public security management is flawed and incapable of effectively identifying and preventing various risks (CAM, 2005). These problems lend extreme urgency to better assess the vulnerability of and the risk to the complex urban system with greater spatial accuracy, improve dynamic prediction ability, and satisfy the requirements on public security planning and emergency decision-making.

Socioeconomic losses caused by natural disasters refer to the damages inflicted by hazards on disaster bearing bodies under the hazard-formative environment (Niu et al., 2012). Blaikie (1994) pointed out that hazards are the prerequisite for disasters, while vulnerability is not only the source of disasters, but also the major reason for the final occurrence of disasters and the difference between disaster losses in different regions. It is difficult to control hazards with existing technologies. Therefore, in urban disaster risk management, the most straightforward and effective approach to reduce disaster losses is to alleviate vulnerability of the socioeconomic system (Shi, 2010).

Many works have been done around the world on social vulnerability (Adger et al., 2004; Cutter and Finch, 2008), but little attention has been paid to economic vulnerability. The economic system is very complex. With ongoing economic globalization, labor is further divided in the society, and the industrial chain is even longer, involving more and more geographically dispersed enterprises, the industrial chain has evolved into a complex network system that consists of suppliers, manufacturers, distributors, wholesalers and retailers located at different regions (or even across the world), their interrelation with numerous participants adds to the complexity of the system. Event at any node in the system will soon affects upstream and downstream enterprises that are related to it, and then the influence will propagate to all enterprises along the chain. Hence, a single emergency may exert heavy impact on the normal operation of the entire industrial chain, making the industrial chain become so vulnerable to the public security event (Yan, 2010). Because the economic system is very complex and difficult to quantify, the studies on economic vulnerability around the world focus on theoretical exploration, without providing a good and recognized method for economic vulnerability assessment (Hiete et al., 2009; Wu et al., 2009). This highlights the urgency about and adds difficulty to the assessment of cities' economic vulnerability.

The rapidly progressing information technology is drawing widespread attention from information sharing and acquisition domains (He et al., 2010) and its application in disaster risk management becomes a novel topic in this context. HAZUS, a multi-disaster loss assessment model, is a well-known example that introduces information technology to disaster management. This model performs risk evaluation on potential losses from disasters, such as earthquake and flood through the use of $3 \mathrm{~S}$ technologies, it is professional but needs a lot of data on population and socioeconomics (Schneider and Schauer, 2006). Besides, there are 
U.S. Emergency Management System, the European EUREKA Major Emergency Intelligent Management System, and the Japanese Disaster Response System (Shabestari et al., 2004; Yin, 1995). Compared with these advances, most of the studies conducted in China on the application of information technology to disaster management are pertaining to the management of data and display of basic information, but lacking the ability of analyzing and processing the data, especially the ability of vulnerability assessment (e.g. effective economic vulnerability assessment method) (Niu et al., 2012; Xie et al., 2000). Thus, few of the current studies can meet the real needs in practice.

To alleviate disaster risks in cities, provide decision-making support for urban public security management in the context of rapid urbanization in China, it is urgently needed to deepen the research on urban economic vulnerability assessment methodologies and develop a good assessment system. To this purpose, we explore the theoretical and methodological issues about urban economic vulnerability at the micro scale, and attempt to establish a GIS-based system for simulating and assessing urban economic vulnerability.

\section{Economic vulnerability assessment}

\subsection{The definition of economic vulnerability}

There are many definitions of economic vulnerability, and it is subject to various interpretations and usage (Saldaña-Zorrilla, 2006). Researchers in China and abroad focus their attention on self-development of macro economy or regional economy, but fail to study in the context of disasters (Li and Zhang, 2008). In this paper, economic vulnerability is defined as the potential degrees of loss inflicted on disaster bearing bodies, consisting of exposure and sensitivity. Sensitivity refers to the probability of loss that the disaster bearing bodies suffer. The product of exposure and sensitivity measures the degree of potential losses that may be inflicted on the economic disaster bearing bodies.

Coping capacity that is recognized by many researchers as an element of vulnerability is not taken into account in this paper, neither do other relevant factors, like resilience. Most of the empirical studies on economic vulnerability which take into account coping capacity are performed at the large regional (Saldaña-Zorrilla, 2006; Adrianto and Matsuda, 2002) or enterprise scales (Tierney, 1999; Chang and Falit-Baiamonte, 2002), and there is no micro-scale study on urban economic vulnerability to the best of our knowledge. The large regional-scale study on vulnerability cannot identify the small-scale changes of economic vulnerability, and it is difficult for the enterprise-scale study to be done across a large region. Therefore, both of them are unable to shed new insights into disaster prevention and alleviation (e.g. urban public security planning and emergency management). In this context, small-scale study on economic vulnerability of the city is done in this paper. However, most of the indicators that can measure the adaptability or resilience of economy cannot be analyzed statistically at a small scale. Due to data availability problem, neither adaptability nor resilience is taken into account here. Just as defined by Wang (2006), vulnerability is also a state variable in this paper.

Enterprise is the basic unit of the disaster bearing bodies. For individual enterprises, exposure can be roughly measured by total assets of the enterprises. It is impractical to evaluate the sensitivity of enterprises one by one. Taking into account tradeoff between accuracy 
and feasibility, we estimate the sensitivity of industrial sectors in the three-digit (most are three-digit, still some are two-digit or four-digit) list of industries announced by National Statistics Bureau of China, and use the sensitivity of industrial sectors to which the enterprises belong to substitute the sensitivity of enterprises. This is feasible and reasonable. Hence, the economic vulnerability of an enterprise is defined as the product of the enterprise size (exposure) and the sensitivity of industry.

\subsection{Type of disasters}

The economic losses that may be inflicted on disaster bearing bodies vary according to the types of disasters. Our focus is on the highly influential disaster and earthquake is chosen as the potential disaster in this paper. The peak ground acceleration (PGA) as a measure of the seismic risk index is almost the same across the entire Haidian District, and it changes slightly for the entirety of Beijing. So the economic losses inflicted on each area of Haidian District are mainly dependent on its own socioeconomic properties. Detailed illustration is given below.

The vulnerability of the economic system is given by:

$$
V(R)=V(I, S)
$$

where $V$ denotes the economic vulnerability index of the region $R, I$ denotes the intensity and probability of external interference, $S$ denotes the economic system which is a set of socioeconomic factors that may influence vulnerability. $I$ and $S$ interact with each other to yield exposure, and sensitivity is an internal property of $\mathrm{S}$.

When the entire region is subject to external interference of the same intensity and probability, economic impact of disasters on different areas is a function of its own economic properties. So the above equation can be simplified into:

$$
V(R)=V(S)
$$

Natural hazards have been extensively studied in China, but little attention has been paid to the vulnerability that is influenced by the internal socioeconomic properties of areas. This paper is focused on the economic vulnerability determined by the economic system's own properties.

\subsection{Factors in economic vulnerability}

Hiete and Merz (2009) summarized the types and sources of losses inflicted by disasters on industries. As the disaster bearing bodies, the enterprises usually suffer the following losses in case of disaster: (1) direct economic losses: damages to production equipment, raw materials and stocks, which can be measured by total assets of the enterprises; (2) losses caused by the supply chain disruptions: production disruption in an enterprise will influence other enterprises upstream and downstream, resulting in indirect losses; (3) production losses result from outages within critical infrastructure; (4) other losses, such as the secondary disasters (e.g. explosions and release of hazardous substances) in special industries (e.g. the chemical industry). Due to data availability and computation complexity in practice, it is difficult to quantify all losses inflicted on each enterprise. Therefore, for an area involving many enterprises, the sensitivity of the industry is used as a substitution for that of the enterprises in the industry.

The sensitivity levels of different industries are estimated by combining the susceptibility 
and importance indices of these industrial sectors. Susceptibility reflects the possibility of loss, and different industries have distinct susceptibility to disasters. Importance reflects the role of certain industries in emergency management and emergency rescue such as food, water supply and medical production, and that the disruption of some crucial industries to daily running of cities may lead to serious consequential damages. A semi-quantitative approach is adopted to select susceptible and important industries. Based on the selected industries, the industrial susceptibility and importance can be quantified by Delphi method.

We also take economic density as a supplement of the economic exposure to disasters. Given limited resources, greater economic profits can be achieved by giving priority to areas with high economic density over areas with low economic density (e.g. agricultural villages).

To sum up, economic vulnerability is influenced by enterprise size, industrial susceptibility, industrial importance, and economic density.

\subsection{Models for economic vulnerability assessment}

\subsubsection{The comprehensive model for economic vulnerability assessment}

We study the functional relationship between the above mentioned factors to establish the evaluation model. Vulnerability can be assessed by the product of exposure and sensitivity (Adger, 2006). Accordingly, the product of enterprise exposure and the sum (which can represent the sensitivity) of susceptibility and importance of industries can measure the vulnerability of the enterprises. The vulnerability of enterprises and the economic density are two complementary components. Thus, the following assessment model is established:

$$
V=\sum_{n} \alpha^{*} S *\left(\beta^{*} X_{1}+(1-\beta) * X_{2}\right)+(1-\alpha) * X_{3}
$$

where $V$ is the regional economic vulnerability; $S$ is the enterprise's size, representing the exposure; $X_{1}$ and $X_{2}$ are indices of industrial susceptibility and importance, respectively; $\mathrm{n}$ is the number of enterprises in this region; $X_{3}$ is the economic density of this region, and $\alpha, \beta \in$ $[0,1]$ are weighting parameters. As $X_{1}, X_{2}$ and $X_{3}$ carry different physical meaning, their values should be standardized in order to obtain the overall level of economic vulnerability of the concerned region.

The economic vulnerability assessment model involves four factors, enterprise size, industrial susceptibility, industrial importance, and economic density, highlighting the need to first evaluate each factor.

\subsubsection{Assessment on industrial susceptibility}

Tierney (1997) summarized that the losses caused by disasters consist of (1) direct physical losses, (2) production losses result from disruptions of critical infrastructure and (3) losses caused by the supply chain disruptions, based on this, factors influence industrial susceptibility can be grouped into three main types: factors for input factor dependency, for infrastructure dependency and for supply chain dependency. The influence mechanism of factors on industrial susceptibility is summarized in Table 1. The chosen indicators for input factors include the educational background of employees, professional title, intermediate input rates, total assets, etc. Supply chain dependency can be expressed via indicators such as influence coefficient, which depict the relative dependence degree of certain industrial sectors on the 
supply chain in a very simplified but manageable (using input-output tables) way. The assumption made here is that industries with larger influence coefficients which indicate that the industries need more input from the other sectors are more susceptible to supply interruptions. We choose water consumption, electricity consumption and transportation volume (road and railway) of each industrial sector as indicators to measure the industry's dependence on lifeline systems. The ratio of the total output value of an industry to the total GDP of the entire region is used to measure the spatial agglomeration degree of the industries.

Table 1 Influencing factors of industrial susceptibility and underlying mechanism

\begin{tabular}{ll}
\hline \multicolumn{1}{c}{ Influencing factors } & \multicolumn{1}{c}{ Mechanism } \\
\hline $\begin{array}{l}\text { 1. Supply shortage or damage of input } \\
\text { factors (labor, capital, equipment, raw } \\
\text { material, etc.) }\end{array}$ & $\begin{array}{l}\text { An industry is more susceptible if its input requirements are higher and } \\
\text { more specialized (e.g., highly educated and skilled workers, high value } \\
\text { equipment, high intermediate input rate, capital requirements), such in- } \\
\text { dustries may encounter greater direct losses and the possibility of produc- } \\
\text { tion interruption due to poor input factor substitution is higher. }\end{array}$ \\
\hline $\begin{array}{l}\text { 2. Disruption of lifeline systems (water, } \\
\text { electricity, transportation volume) }\end{array}$ & $\begin{array}{l}\text { An industry is susceptible if it is highly dependent on lifeline systems, } \\
\text { e.g., extensive consumption of electricity, water and energy and transpor- } \\
\text { tation facilities, because it is more likely to be affected by the disruption } \\
\text { of lifeline systems. }\end{array}$ \\
\hline 3. Supply chain interruption & $\begin{array}{l}\text { Industries with large backward linkage effect (demand for the upstream } \\
\text { industries) are more susceptible to the interruption of upstream industries. }\end{array}$ \\
\hline 4. Degree of industrial agglomeration & $\begin{array}{l}\text { An area is expected to be more susceptible if the industries are more } \\
\text { agglomerated in this area because of greater exposure to disasters. }\end{array}$ \\
\hline
\end{tabular}

We perform a weighted summation on the non-dimensional values of the above mentioned indicators and then make preliminary selections of susceptible industries. We also supplement some susceptible industries by scrolling through the literature at home and abroad (Du and Zhang, 2008; Deng, 2008; Chen, 2008; Yang, 2008) as well as media information. Eventually, 69 susceptible industries are identified.

The Delphi method is adopted to assess the susceptibility of these industries. Specifically, we conduct a questionnaire survey and ask 70 experts in the field of regional economics and disaster science to classify and score the selected industrial sectors: 7 for highly susceptible, 5 for very susceptible, 3 for medium susceptible, and 1 for low susceptible. On this basis, the standardized average scores of industrial susceptibility are calculated. Table 2 shows the results for industrial sectors with high susceptibility.

Table 2 The rating score of the susceptibility of some industrial sectors

\begin{tabular}{lclc}
\multicolumn{1}{c}{ Industrial sector } & $\begin{array}{c}\text { Suscep- } \\
\text { tibility }\end{array}$ & \multicolumn{1}{c}{ Industrial sector } & $\begin{array}{c}\text { Suscepti- } \\
\text { bility }\end{array}$ \\
\hline Nuclear fuel processing industry & 6.27 & Chemical materials and products & 5.14 \\
Nuclear radiation processing industry & 6.21 & Electric power generation & 5.09 \\
Gas production and supply industry & 5.7 & Special chemical products manufacturing & 4.89 \\
Electric power supply & 5.51 & Refined petroleum products manufacturing & 4.86 \\
$\begin{array}{l}\text { Oil processing, coking and nuclear fuel } \\
\text { processing industry }\end{array}$ & 5.34 & Petroleum and natural gas extraction & 4.83 \\
Hydraulic production and supply industry & 5.2 & $\begin{array}{l}\text { Biological and biochemical products manu- } \\
\text { facturing }\end{array}$ & 4.78 \\
\hline
\end{tabular}




\subsubsection{Importance assessment by industrial types}

Important industries include those industries that are crucial to emergency management and those that are significant to other industries' production processes, Industries in the first category are identified through qualitative analysis methods (e.g. literature and media information), while those in the second category are identified by inducing coefficient. Inducing coefficient refers to a comparison of the production needs of one industrial sector caused by one more unit of final product of all industrial sectors and the average level of production needs of the various industrial sectors caused by one more unit of final product of all industrial sectors. Large inducing coefficient indicates that the industry is the basic industry; inducing coefficient can be calculated using the regional Input-Output Table. We also supplement some important industries that are crucial to emergency management by scrolling through the literature and media information (She and Guo, 2008). In this study, 49 important industries are selected. Using the Delphi method as mentioned above: 7 for very high importance, 5 for high importance, 3 for medium importance and 1 for low importance, the average scores of the industrial importance are computed, as shown in Table 3.

Table 3 The rating score of the importance of some industrial sectors

\begin{tabular}{|c|c|c|c|}
\hline Industrial sector & Importance & Industrial sector & Importance \\
\hline Hospital & 6.61 & Gas production and supply industry & 5.96 \\
\hline Hydraulic production and supply industry & 6.49 & Telecommunications profession & 5.73 \\
\hline $\begin{array}{l}\text { Disease prevention, control and epidemic } \\
\text { prevention activities }\end{array}$ & 6.38 & Internet information service & 5.51 \\
\hline Electric power supply & 6.32 & Railway passenger transportation & 5.45 \\
\hline $\begin{array}{l}\text { Hospitals and community health care } \\
\text { activities }\end{array}$ & 6.07 & Urban public transportation & 5.39 \\
\hline Electric power generation & 5.96 & Road freight transportation & 5.34 \\
\hline
\end{tabular}

\subsubsection{Estimation of the size of individual enterprises}

The size of enterprises can be reflected by annual turnover, number of employees and total assets. In order to get a comprehensive evaluator from these three factors, we extract common factors from them with factor analysis method. If the values of the obtained common factors are negative, they are transferred to a positive set by the following formula:

$$
S_{1}=S+\varepsilon
$$

where $S_{1}$ represents the estimated sizes of enterprises; $S$ represents the sizes of enterprises before transformation; $\varepsilon$ is integer absolute value of the minimum value of $S$.

The estimated sizes of individual enterprises are then aggregated for each block.

\subsubsection{Economic density of blocks}

At the block level, economic data in China is not publicly available. According to Alaghi (2012), any tangible or intangible economic resources that are capable of producing value and that hold some positive economic value can be considered as an asset. Therefore, total asset is a better representative of economic scale than GDP. The enterprise dataset provides the total assets of 138,380 enterprises, and the enterprise data is spatially continuous, making it possible to calculate the sum of total assets at any spatial scale. Therefore, the total number of assets of all enterprises in each block is used to represent the total assets of this 
block. The total asset per unit area is calculated for each block to determine the economic density, which eliminates the influence of block area.

\section{Structure and functional modules of the proposed system}

Based on the above discussions, this paper proposes the system for simulating and assessing urban economic vulnerability, performs IT-based management on urban economic vulnerability, and provides a powerful tool for assessing urban economic vulnerability.

\subsection{Functional module}

The objective of the proposed system is to simulate and evaluate urban economic vulnerability via the above models, statistically analyze and visually display the evaluation results, and help cities to make disaster prevention decisions. Functional modules of this system are: data management module, map engineering module, configuration management module, industrial susceptibility evaluation module, industrial importance evaluation module, comprehensive economic vulnerability evaluation module, statistical analysis module, and the module for making thematic maps, as shown in Figure 1.

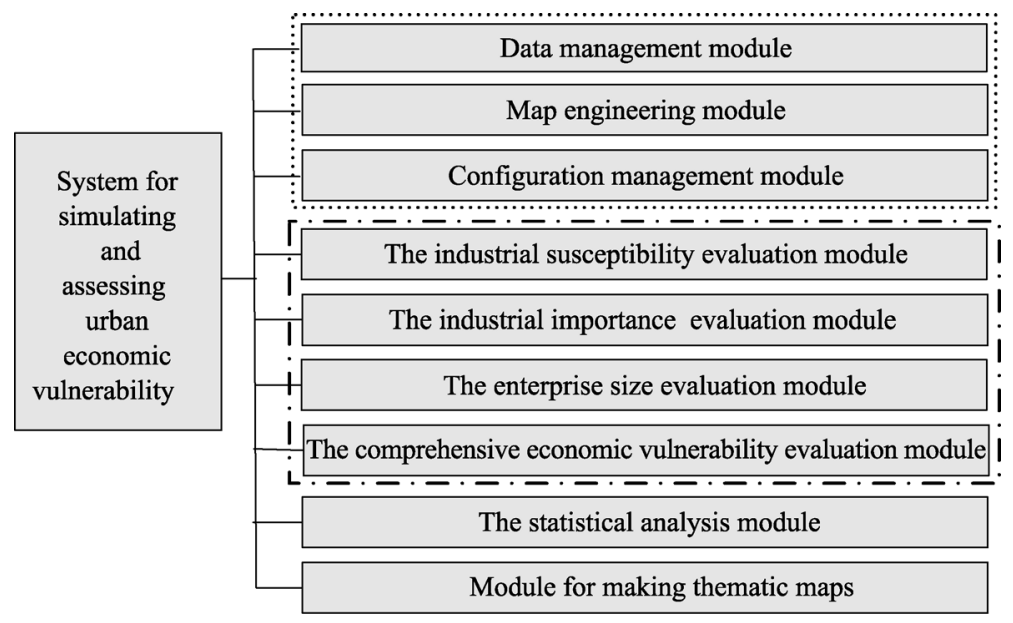

Figure 1 Main functions of the system

(1) Data management module is responsible for reading, writing and editing data, as well as interacting with the data layer and each functional module. Each functional module performs read and write operation via this module. (2) Map engineering module is responsible for performing map operations, including basic GIS functions (e.g. map query, zooming and roaming), visual representation, organization and management of project files. (3) Configuration management module can be used to manage the configurations of system functions, provide customized management for different users, setup and store the environment parameters. This module is designed to serve system operation, like the management of user authorizations as well as the addition and deletion of users. (4) The industrial susceptibility evaluation module, the industrial importance evaluation module, and the enterprise size evaluation module employ the above research achievements and industry data to evaluate urban industrial susceptibility, importance, enterprise size, respectively. (5) The comprehen- 
sive economic vulnerability evaluation module can comprehensively evaluate urban economic vulnerability by using the results from modules in (4) and the data on economic density. (6) The statistical analysis module and the module for making thematic maps can statistically analyze evaluation results and make thematic maps. Both modules are designed as a further extension to vulnerability evaluation, taking into account user needs and application functions, so they are helpful to professional user applications.

The modules in (4) are the core of the proposed system, because it can evaluate the economic vulnerability.

\subsection{System framework and procedures for data processing and analysis}

\subsubsection{System framework}

The system structure is devised based on the above design of functional modules. The system structure consists of three layers: user interface layer, core operation layer and layer of data center, as shown in Figure 2 (the bottom layer is the operating system and the database management system, etc.).

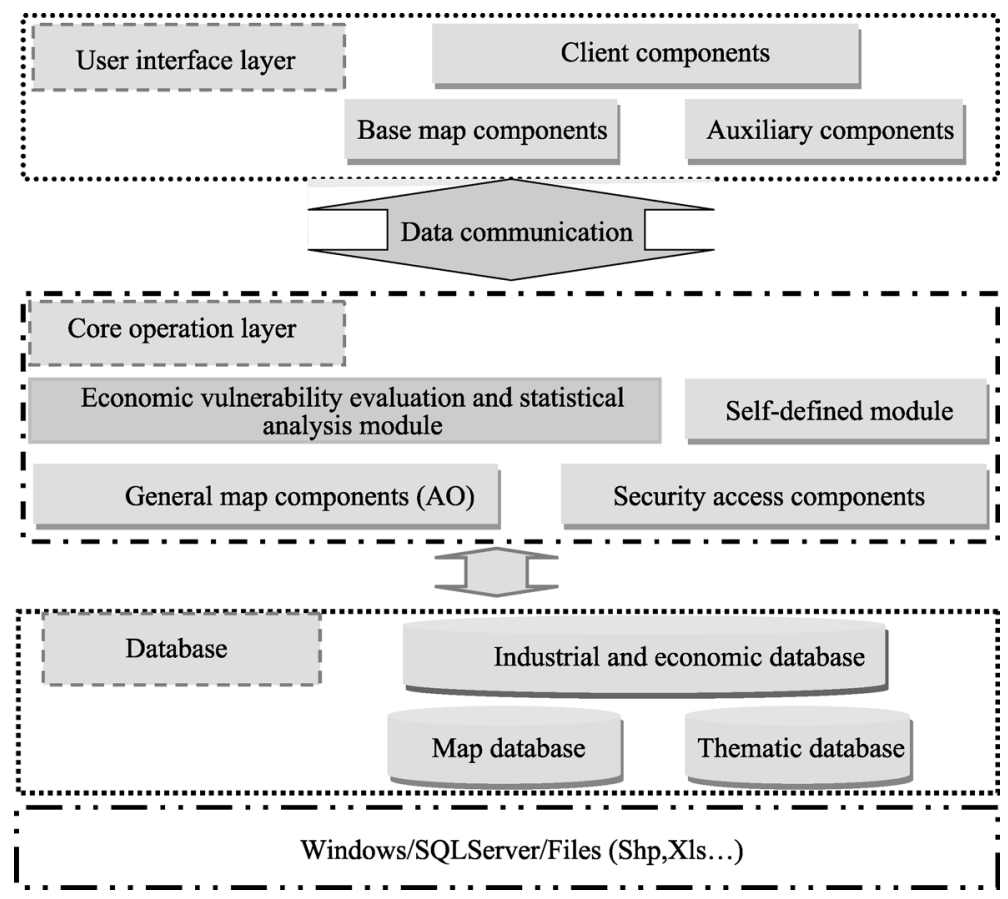

Figure 2 Framework of the system

(1) User interface layer

The user interface layer is the system's user client and provides users with operation interface. GIS-based virtual user interface is developed, enabling users to intuitively operate via the map so that the evaluation results can be displayed visually.

(2) Core operation layer

This layer executes core operations and implements each evaluation module of the system. In addition to the evaluation function of the system, this layer also implements statistical 
analysis function. To accommodate different application needs of users, this layer offers the module that allows users to self-define the model. With this module, the users can setup model parameters, define different evaluation models and improve the generalization of system. In this layer, the AO (Arc Object) data access control is used for interacting with the data layer (read and write data).

(3) Data center

This layer is responsible for reading and writing data, including the map data and the industrial data. The spatial data format (SHP file) introduced by ESRI is used in this paper. The SHP file stores the spatial and attribute data in an integrated manner for ease of operation. In the experiment, the industrial and economic data is defined as the attribute data of the shapefile to create the integrated SHP file and facilitate system processing. Furthermore, the industrial and economic data is usually stored separately into the Excel file, therefore, for ease of use, the system provides the data link function, allowing users to associate the industrial economic data with the map file via the integrated field, as well as enabling map-based calculation, statistical analysis, query and virtual representation.

\subsubsection{System procedures for processing and analyzing data}

After logging on the system, the user should first input the economic and map data. The system then uses the data to assess the economic vulnerability, yielding the assessment results regarding industrial susceptibility, industrial importance, enterprise size, as well as economic vulnerability. Therefore, the data flow (as shown in Figure 3) can be divided into data input (data read), data analysis (statistical analysis), data processing (vulnerability evaluation), and data output (visual representation). Visual representation provides the functions of vulnerability hierarchical rendering and thematic mapping.

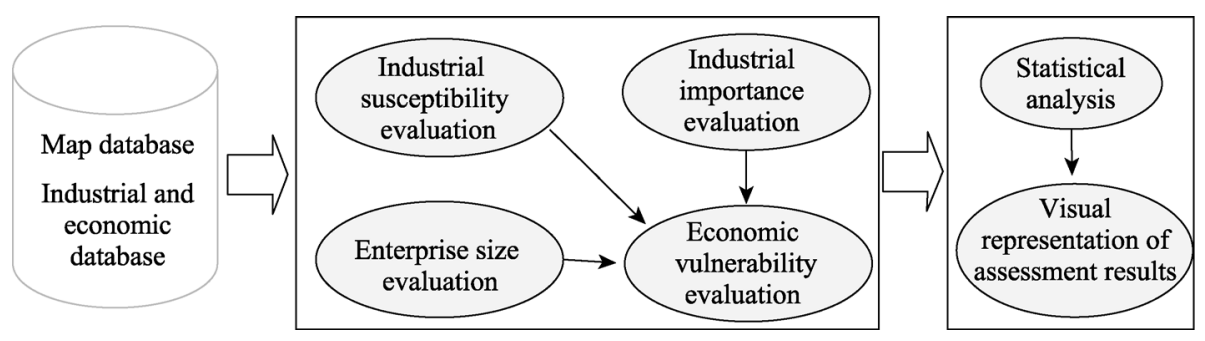

Figure 3 Flow chart of system processing

\section{System implementation and application}

\subsection{System implementation}

Based on the above discussions as to factors influencing economic vulnerability, evaluation models and system framework, the DEMO system is proposed to simulate and evaluate economic vulnerability. The proposed system is developed using Visual Studio2008, C\# and the Arc Object map components from ESRI.

Each parameter in the model is stored as a file in the system directory. That is, the corresponding model parameters will be read automatically when the system runs, the initial default settings defined by the parameters are shown in Tables 2 and 3. Users can edit the pa- 
rameter file through Text Editor, thereby resulting in greater system generalization. The virtual representation function of the system can plot the vulnerability assessment results, more intuitively displaying the spatial distribution of vulnerability.

\subsection{Case study}

\subsubsection{Study area and data}

In 2012, the GDP of Beijing is 1787.94 billion yuan, with a population of 20.69 million. As a megacity, Beijing has a huge exposure to disasters and is confronted with many natural and human-caused perturbations or stressors. A case study of economic vulnerability assessment is conducted in Haidian District, one of its eight central districts. Haidian District covers an area of $431 \mathrm{~km}^{2}$, and is located in north-west Beijing, with the southern part being built-up areas and the northern part hilly mountain areas. The district has 29 lower level administrative units (Figure 4), called Jiedaos and Townships.

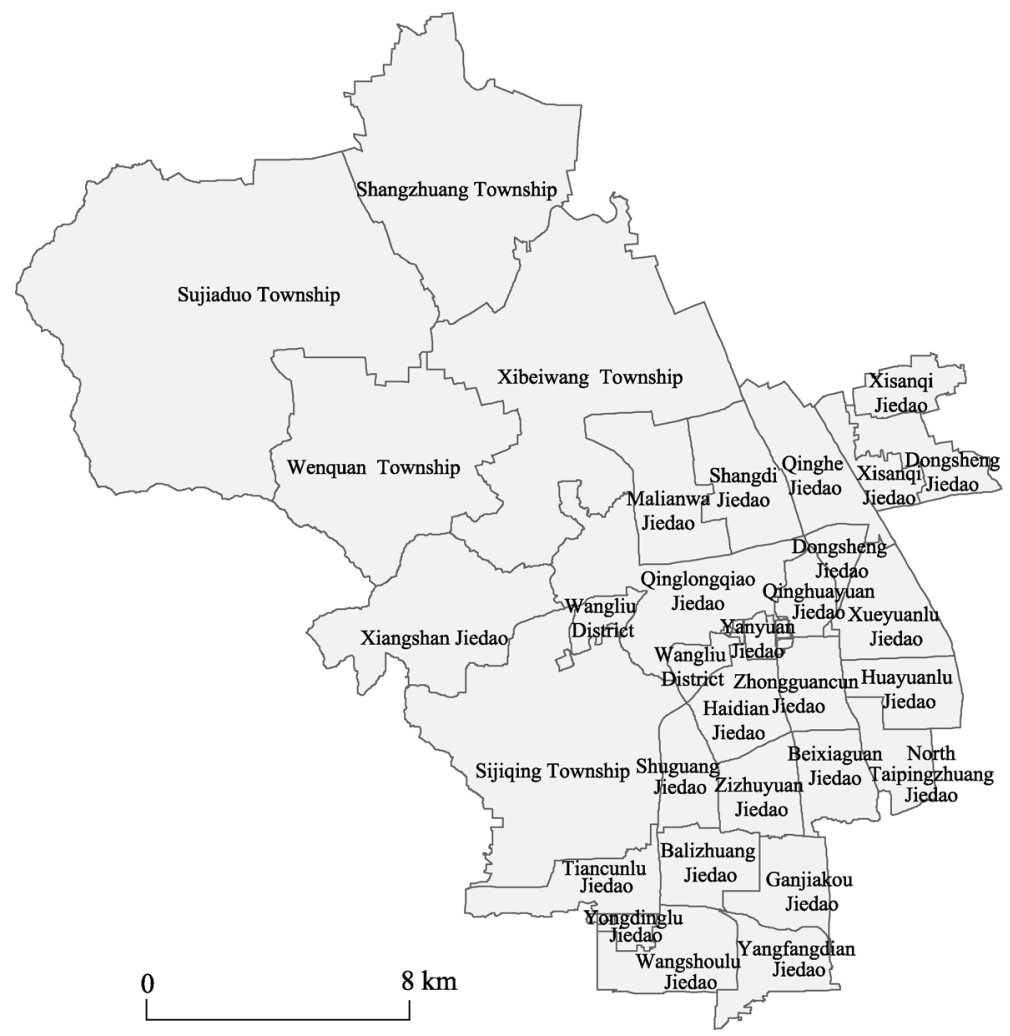

Figure 4 The administrative division of Haidian District in Beijing

Data are derived from a variety of sources, such as the water consumption from the 2010 Annual Statistic Report on the Environment in China, electricity consumption from Beijing Statistical Yearbook 2011, traffic amount data from the Highway and Waterway Transportation Industry Statistical Bulletin in 2010, intermediate input rate, influence coefficient and induction coefficient are calculated with data from the 2010 Input-output Table of 42 Departments in Beijing, and the educated and professional levels of employees from The Sec- 
ond National Economic Census Data Bulletin of Haidian District 2008. Moreover, registered enterprise data in Haidian District in 2010 are used. The dataset includes 138,380 firms and provides a wide range of information including annual turnover, total assets, number of employees, registered capital, industry code (in two-, three- and four-digit)corresponding to Standard Industry Classification, ownership type, founding time, and location. The enterprises are then mapped as a point layer with the geo-coding function of ArcGIS.

\subsubsection{The definition of spatial unit}

Appropriate scale should be predicated upon research goals. In order to identify the vulnerable places, industries in urban areas as well as to draw useful implications for relevant policies, we take blocks as the basic spatial unit in this study, considering that blocks, which are confined by urban roads, constitute the basic unit of urban fabric and the smallest component in urban planning and spatial governance (Xiao, 2006).

To focus on urban areas, the northern part of Haidian District which mainly consists of forest and agricultural land use is taken out from the study area. Then, with ArcGIS application, the study area is divided by urban roads into 647 blocks.

\subsubsection{Parameter selection}

It is difficult to assign values to parameters of economic vulnerability assessment model in equation (3). This is a disadvantage of the indicator system approach. In previous studies on economic vulnerability assessment, weights were often determined subjectively based on experience or via expert scoring (Adrianto et al., 2002). This is improved in our study by performing statistical test on the stability of economic vulnerability with varying parameters. Parameters $\alpha$ and $\beta$ are set to values range from 0.3 and 0.7 with intervals of 0.1 , yielding 25 combinations, which are applied to the model. Results show that the coefficients of variability are less than $30 \%$ for all 647 blocks, and that of blocks at the level of high economic vulnerability are less than $20 \%$, indicating that the economic vulnerability is not very sensitive to weight parameters. Taking this into account and referring to some relevant literature (Adrianto et al., 2002; Briguglio, 1995), we assign 0.5 and 0.6 to $\alpha$ and $\beta$, respectively.

\subsubsection{Analysis results}

Based on above data, the DEMO system is used to simulate and evaluate urban economic vulnerability, results are shown in Table 4.

Table 4 Statistics of blocks by economic vulnerability levels

\begin{tabular}{cccc}
\hline \multirow{2}{*}{ Vulnerability levels } & $\begin{array}{c}\text { Number of } \\
\text { blocks }\end{array}$ & Percentage (\%) \\
\cline { 3 - 4 } & 330 & 51.00 & By area \\
\hline Low & 214 & 33.07 & 73.10 \\
Medium & 65 & 10.04 & 3.71 \\
High & 38 & 5.87 & 1.20 \\
Very high & & By number & . \\
\hline
\end{tabular}

Table 4 shows the overall economic vulnerability of Haidian District. Of the 647 blocks, 103 blocks, which account for $4.91 \%$ of the area of Haidian, face high and very high economic vulnerability. 
Figure 5 shows that blocks with high and very high economic vulnerability are mainly concentrated in the southern urban living and service area, and the eastern high-tech industrial parks. Western tourism and agricultural areas have low economic vulnerability. Overall, economic vulnerability decreases spatially from the southeastern urban areas to the northwestern suburbs and villages. The spatial agglomeration areas of high and very high economic vulnerability are Zhongguancun, Haidian, North Taipingzhuang, Ganjiakou, Shangdi, North Xiaguan, Yangfangdian, Wanshoulu, and Zizhuyuan Jiedaos. Specifically, blocks with high and very high economic vulnerability are highly concentrated in Zhongguancun, Haidian, North Taipingzhuang, Ganjiakou, and Shangdi Jiedaos. According to Beijing Haidian Municipal Commission of Urban Planning, these regions have been the agglomeration areas of high-tech industries, commercial, exhibition, medical, and the government services, all of which play important roles in Haidian's economy as well as that of Beijing. We, therefore, suggest that more attention should be paid to these areas in emergency management and daily risk management.

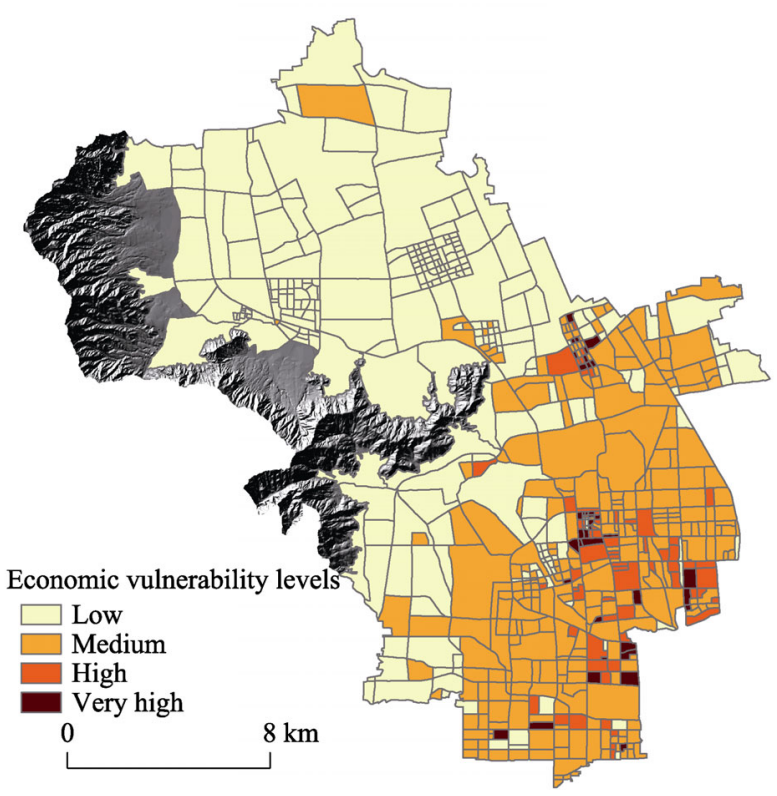

Figure 5 Distribution of blocks by economic vulnerability levels of Haidian District in Beijing
The results in Figure 5 accurately show the economic vulnerability of each block in the city, and the evaluation is performed at a greater spatial accuracy. Each factor in economic vulnerability, like the size and distribution of industrial enterprises, is also shown in real-time. In the case of changes in spatial distribution of enterprises or the economy, for example, a new enterprise that poses potential hazards moves to the area, the economic vulnerability of the entire area can be easily updated by predicting under the new circumstances. This substantially improves its dynamic prediction ability. Therefore, our work is very helpful for public security planning and emergency decision-making.

\section{Conclusions}

This paper explored the factors that influence economic vulnerability and established an economic vulnerability assessment model. On this basis, an urban economic vulnerability evaluation system was developed. Several progresses were made.

(1) We succeeded in carrying out economic vulnerability assessment at the level of city blocks, which provided precise information for decision-making in disaster management. Previously, the selection of spatial scale depended more on the availability of data rather than on actual needs, and the basic spatial units being used were often too large to be suit- 
able. By examining the effects of taking city block as the basic unit, we discovered that the quality of the assessment was significantly improved.

(2) We developed an economic assessment model considering enterprise size, economic density, and the susceptibility and importance of various industrial sectors. Susceptibility and importance are very important notions for the vulnerability of industrial sectors and this model suggested a theoretical direction of relevant studies.

(3) A system for simulating and assessing economic vulnerability was proposed, which provided a powerful tool for assessing economic vulnerability. The model and the proposed system not only gave decision makers a better understanding of the distribution of urban economic vulnerability, but also provided useful and precise information for disaster prevention and emergency management. As an exploratory step towards the IT-based risk management of disasters, the proposed system ran well and shed light on future development.

Further work needs to be done in the following aspects. First, the urban economic vulnerability assessment methodology is to be improved. In this study, we only discussed the relation of the industry with the local economy, but the relation of the industrial chain is not necessarily limited to the spatial scope of a single city. In metropolitan areas, the structures and interactions of different industrial sectors are extremely complicated and the vulnerability of urban areas to different kinds and intensity of disasters may differ. Second, our study only considered a limited number of selected aspects and factors, and some measures and parameters still relied much on expert knowledge and experience. For simplicity, the intensity of disaster influence and interactions between the bearing economic system and disasters were neglected, while considering earthquake as the potential disaster, it is implicitly assumed that the entire region faces earthquake of the same magnitude, consequently, the theoretical model of economic vulnerability is a function of the region's internal conditions. These factors should be better considered and how to incorporate them into the model will be the direction for future studies. Moreover, with widespread network applications, the B/S (Browser/Server) structure is more preferable for users. Thus, implementing the $\mathrm{B} / \mathrm{S}$-based application system is also expected.

\section{References}

Adger W N, 2006. Vulnerability. Global Environmental Change, 16(3): 268-281.

Adger W N, Brooks N, Bentham G et al., 2004. New indicators of vulnerability and adaptive capacity. Norwich: Tyndall Centre for Climate Change Research.

Adrianto L, Matsuda Y, 2002. Developing economic vulnerability indices of environmental disasters in small island regions. Environmental Impact Assessment Review, 22(4): 393-414.

Alaghi K, 2012. Asset and systematic risk. African Journal of Business Management, 6(9): 3504-3509.

Blaikie P, Cannon T, Davis I et al., 1994. At Risk: Natural Hazards, People's Vulnerability, and Disasters. London: Routledge.

Briguglio L, 1995.Small island developing states and their economic vulnerabilities. World Development, 23(9): $1615-1632$.

Chang S E, Falit-Baiamonte A, 2002. Disaster vulnerability of businesses in the 2001 Nisqually earthquake. Global Environmental Change Part B: Environmental Hazards, 4(2): 59-71.

Chen X J, 2008. Effects on the economy of earthquake. Shanghai Securities News, 2008-05-22(6). (in Chinese)

China Association of Mayors (CAM), 2006. China Urban Development Report 2005. Beijing: China City Press. 
(in Chinese)

Cutter S, Finch C, 2008. Temporal and spatial changes in social vulnerability to natural hazards. In PNAS, 105(7): 2301-2306.

Deng Y J, 2008. Effects of earthquake on eleven industries. Chinese Modern Enterprises, 2008-05-20(3). (in Chinese)

Du J K, Zhang Q, 2008. Assessment method of indirect economic loss from Wenchuan M8.0 earthquake. Journal of Catastrophology, 23(4): 130-133. (in Chinese)

He Y W, Su F Z, Du Y Y et al., 2010. The design and implement of marine environmental information grid platform. Geo-information Science, 12(5): 680-686. (in Chinese)

Hiete M, Merz M, 2009. An indicator framework to assess the vulnerability of industrial sectors against indirect disaster losses. International ISCRAM conference, Gothenburg (Sweden).

Jiang F R, J B, 2012. Impact of super thunderstorm on 21 July in Beijing and countermeasures. China Water Resources, (15): 19-22. (in Chinese)

Li H, Zhang P Y, 2008. Economic system vulnerability of mining cities in northeast China. Journal of China Coal Society, 33(1): 116-120. (in Chinese)

Niu F Q, Gao X L, Ji J, 2012. A house damage evaluation system of regional long-term seism in China. Resources Science, 34(2): 359-366. (in Chinese)

Niu W Y, 2004. China Urban Development Report (2002-2003). Beijing: The Commercial Press. (in Chinese)

Saldaña-Zorrilla S O, 2006. Reducing economic vulnerability in Mexico: Natural disasters, foreign trade and agriculture. WU Vienna University of Economics and Business.

Schneider P J, Schauer B A, 2006. HAZUS: Its development and its future. Natural Hazards Rev., 7(2): 40-44.

Shabestari K T, Yamazaki F, Saita J et al., 2004. Estimation of the spatial distribution of ground motion parameters for two recent earthquakes in Japan. Tectonophysics, 390(1-4): 193-204.

She L, Guo X, 2008. Industry policy of China's emergency rescue: Lessons learned from Wenchuan earthquake. Journal of Huazhong University of Science and Technology (Social Science Edition), (4): 65-71. (in Chinese)

Shi Y, 2010. Research on vulnerability assessment of cities on the disaster scenario: A case study of Shanghai city [D]. Shanghai: East China Normal University. (in Chinese)

Tierney K J, 1997. Business impacts of the Northridge earthquake. Journal of Contingencies and Crisis Management, 5(2): 87-97.

Wang J A, Shi Z H, Liu Z et al., 2006. Assessment and regional difference of disaster resilience capability in China. Journal of Natural Disasters, 15(6): 23-27. (in Chinese)

Wu J D, Li N, Wen Y T et al., 2009. Economic impact of natural disaster and indirect economic loss estimation methods. Progress in Geography, 28(6): 877-885. (in Chinese)

Xiao L, 2006. The research on urban block [D]. Shanghai: Tongji University. (in Chinese)

Xie L, Tao X, Wen R et al., 2000. A GIS based earthquake losses assessment and emergency response system for Daqing Oilfield. Auckland: 12th World Conference on Earthquake Engineering. (in Chinese)

Yan Y, 2009. Research on prevention strategies and response methods for the resilient supply chain network [D]. Shenyang: Northeastern University. (in Chinese)

Yang H X, 2008. Four effects of earthquake on real estate industry. China Real Estate News, 2008-05-26(23). (in Chinese)

Yin Z E, 2009. Research of urban natural disaster risk assessment and case study [D]. Shanghai: East China Normal University. (in Chinese)

Yin Z Q, 1995. Content of analyzing earthquake losses in city and the process of countermeasures decision-making for disaster mitigation. Chinese Science Abstracts Series B, 14(3): 60. (in Chinese)

Yu H H, Yu Q, 2005. Supervision of the major risk sources and emergent rescue system in big cities. China Safety Science Journal, 15(9): 96-99. (in Chinese) 